\title{
El libro y la provocación del sentido*
}

\section{Gastón Gaínza}

\author{
Universidad de Costa Rica
}

\section{RESUMEN}

Se analizan las nuevas condiciones y el papel que desempeña el libro como objeto cultural en la sociedad capitalista contemporánea. Plantea y describe las dif erencias sustanciales entre la industria del libro como objeto-mercancía, y la idea del libro como trabajo textual y, en consecuencia, como hecho sociocomunicador. En ese proceso, los textos transgreden el discurso del poder, lo limitan y lo ponen en evidencia; es decir, provocan un sentido crítico.

\section{Abstract}

An analysis is presented of the new conditions and the role that books have as a cultural object in the contemporary capitalistic society. This article describes the main differences between the publishing industry where the book is seen as an object-as merchandise - and the notion of a book as textual work, and thus as a socio-communicative event. In this process, texts transgress power, limit it and make it evident; that is, they foster critical awareness.

"Y dime, Sancho amigo, ¿qué es lo que dicen de mí por ese lugar?" Así pregunta Don Quijote a su escudero en el segundo capítulo

* Charla dada en la Biblioteca Joaquín García Monge de la Universidad Nacional de Costa Rica con motivo de la celebración del Día del Libro (23 de abril de 2004). 
de la segunda parte del libro. Y la respuesta de Sancho, una vez que logra que su amo le asegure que no se enojará con lo que dijere, culmina con la alusión al hijo de Bartolomé Carrasco, "que viene de estudiar de Salamanca, hecho Bachiller", quien le ha dicho:

que andaba ya en libros la historia de vuesa merced, con nombre de El ingenioso hidalgo Don Quijote de la Mancha, y dice que me mientan a mí en ella con mi mismo nombre de Sancho Panza, y a la señora Dulcinea del Toboso, con otras cosas que pasamos nosotros a solas, que me hice cruces de espantado cómo las pudo saber el historiador que las escribió ${ }^{1}$.

Admirado Don Quijote con la nueva, autoriza a Sancho para que vaya en busca del bachiller Sansón Carrasco, encuentro que sirve de materia para el capítulo siguiente, uno de los más graciosos de nuestra obra insigne que, en este día, es referente inexcusable de la conmemoración del libro.

Con todo, lo sorprendente del acontecimiento narrado, equivalente a un núcleo de sentido, reside en la toma de conciencia, por parte de ambos personajes, de que "su historia" anda en libros; esto es, ha accedido a un nivel superior de la existencia cultural de la época, el que determina la escritura.

En rigor, de acuerdo con el texto, Sancho dice que el Bachiller le contó que la historia de Don Quijote "andaba ya en libros". Si se repara en el tiempo verbal empleado, "andaba", y en el adverbio temporal "ya", los ejes referenciales de este núcleo narrativo sobrepasan la mera denotación de lo que está aconteciendo: 'la historia de Don Quijote está escrita'. En efecto, los semas deícticos de dichos lexemas agregan una carga significativa no desdeñable, como lo demuestra un análisis más demorado.

1. Miguel de Cervantes Saavedra, El ingenioso hidalgo Don Quijote de la Mancha (Madrid: Ediciones Castilla, 1966. Edición IV Centenario) 495. 
Al emplear el copretérito "andaba" en lugar del presente "anda", que hubiese servido para satisfacer el propósito comunicativo básico, Sancho sitúa el acontecimiento en el pasado, en un 'entonces' que se opone al 'ahora' de la situación comunicativa; junto con la mención de tiempo pasado, la forma verbal remite, en este caso, también a la deixis espacial de un 'allá', en oposición al 'aquí' de la situación comunicativa. De esta manera, cobra relieve el hecho de que este saber fue adquirido en otro lugar ${ }^{2}$, en Salamanca, donde Sansón Carrasco se ha convertido en Bachiller. En la España de Cervantes, el contexto de la obra remite a una distinción geocultural entre La Mancha y Salamanca, manifiesta, entre otras determinaciones, en la oposición entre lo rural y lo urbano, entre lo oral y la escritura, entre el saber cotidiano y el erudito.

Por su parte, el adverbio "ya", mostrativo del tiempo pasado, dentro del núcleo narrativo, significa también la inmediatez, la brevedad del lapso transcurrido entre el tiempo de los acontecimientos vividos por los personajes, su 'entonces', y el 'ahora', momento en que se ha escrito la historia de los mismos. De este modo, los términos "historia" e "historiador" que el narrador utiliza adquieren una carga semántica complementaria que se suma al significado coloquial que en ese tiempo tenían; de la mención anecdótica de relato y narrador, acceden a la de testimonio escrito y erudito, lo que a su vez convierte los acontecimientos vividos por Don Quijote y Sancho en realidad famosa, digna de registrarse en la Historia con mayúscula; y transmuta el tiempo de los acontecimientos narrados en tiempo "historizado".

Este acontecimiento del Quijote pone de manifiesto uno de los recursos retóricos clásicos para la legitimación de la ficción narrada como si se tratase de sucesos reales: la inserción del libro dentro del libro; o, como dice Iuri M. Lotman, del texto en el texto ${ }^{3}$. Pero, ante

2. Repárese en que el espacio en este episodio ha sido distribuido entre el 'aquí' de la situación comunicativa: la de la plática de Don Quijote y Sancho; el 'ahí' del entorno de Sancho, mostrado en la pregunta que le hace Don Quijote: “iqué es lo que dicen de mí por ese lugar?”, y el 'allá' de Salamanca.

3. 'El juego con la oposición 'real - convencional' es propio de cualquier situación de 'texto en el texto'. El caso más simple es la inclusión en el texto de un sector codificado con el mismo código que todo 
todo, establece con extraordinaria lucidez la importante función del libro, como clase privilegiada de textos, en la configuración histórica de la cultura en que estamos inmersos. Procuraré motivar algunas reflexiones sobre la naturaleza de este objeto cultural.

\section{Las amenazas del hipercapitalismo mundializado}

En nuestra experiencia cotidiana actual, sabemos que los libros son mercancías producidas por la industria editorial. Podemos comprarlos en tiendas de diversa índole, aunque las más idóneas, como su nombre lo indica, son las llamadas librerías; a pesar de que, en ciertos casos, se confunde en ellas la venta de libros con otros artículos. Algo similar sucede con los almacenes de grandes superficies, o supermercados, entre cuyos correspondientes artículos aparecen, como rara avis, los libros.

A este saber cotidiano, podemos sumarle otro u otros. Así, por ejemplo, que un libro es un texto impreso en soporte de papel; también, que, por su forma y contenido, un libro posee, por lo general, una condición cultural superior a otros objetos de comunicación impresos. Como en todo saber social más intuitivo que reflexivo, estas cualidades que les asignamos a los libros —a las que podríamos sumar muchas más - son susceptibles de análisis críticos que pondrían de manifiesto su relatividad. Con todo, los libros desempeñan una importante función en nuestra existencia; esta es una verdad incuestionable. A través de ellos, logran permanencia actos comunicativos pertenecientes a todos los géneros discursivos de una reproducción social histórica.

\footnotetext{
el restante espacio de la obra, pero duplicado", Iuri Lotman, La semiosfera, I. Semiótica de la cultura y del texto (selección y traducción del ruso: Desiderio Navarro, capítulo final de Manuel Cáceres, Madrid: Ediciones Cátedra, 1996) 103. Lo significativo de la perspectiva con que Lotman examina este recurso reside en la importancia que él asigna a las funciones culturales del texto: "El aspecto pragmático es el aspecto del trabajo del texto, ya que el mecanismo de trabajo del texto supone cierta introducción de algo de afuera en él. Sea eso 'de afuera' otro texto, o el lector (que también es 'otro texto'), o el contexto cultural, es necesario para que la posibilidad potencial de generar nuevos sentidos, encerrada en la estructura inmanente del texto, se convierta en realidad", ibídem, 98.
} 
Como dije antes, todo libro es un texto; esto es, un objeto semiótico semánticamente autónomo. El texto supone una red de relaciones entre su productor (o destinador), el canal de circulación y su receptor (o destinatario), enmarcadas por unas condiciones de producción semióticas específicas, correspondientes a las determinaciones culturales del grupo social en que se produce el texto. Este marco es lo que, en nuestros días, se llama la semiosfera, término creado por Lotman en consonancia con el de biosfera ${ }^{4}$.

Los libros se producen en una cultura: "La cultura es un generador de estructuralidad, y con ello crea alrededor del hombre una esfera social, que, como la biosfera, hace posible la vida, cierto es que no la orgánica, sino la social"s. En un mismo movimiento, son productos de la cultura y, a la vez, crean nuevos mecanismos culturales. Codificados con el sistema sígnico verbal llamado escritura, participan activamente en los procesos de estructuración del mundo social: "El 'trabajo' fundamental de la cultura (...) consiste en organizar estructuralmente el mundo que rodea al hombre"6. Pero, simultáneamente, en las actuales condiciones de producción, los libros también son mercancías y, como tales, están sujetos a las leyes del mercado.

En este sentido, el proceso de mundialización del hipercapitalismo o capitalismo salvaje, que caracteriza a nuestra época - proceso que algunos llaman globalización, erróneamente-, ha creado unas condiciones de producción editorial que impiden el desarrollo pleno de una cultura del libro, cuyos fines indispensables para el crecimiento de las personas son la conciencia de su mismidad, la capacidad crítica para evaluar su condición histórica y la necesidad permanente de la solidaridad y el respeto a la vida.

\footnotetext{
4. "La semiosfera es el espacio semiótico fuera del cual es imposible la existencia misma de la semiosis", Lotman, La semiosfera, I, 24. Para lo concerniente a la red de relaciones semióticas en que siempre está inserto un texto, es muy significativa la categoría de 'función sociocomunicativa' que Lotman atribuye a los textos. V. "La semiótica de la cultura y el concepto de texto", ibíd., 77-82.

5. Iuri Lotman, La semiosfera, III. Semiótica de las artes y de la cultura (sel. y trad.: D. Navarro, Madrid: Ediciones Cátedra, 2000) 171.

6. Ibídem.
} 
Lo que llamo 'cultura del libro' es la inserción de las diversas y variadas estructuras del sentido que fluye por los textos en las fuerzas productivas de la semiosis social, que es la dimensión semiótica de la existencia colectiva. En sociedades carenciales y asimétricas, como la nuestra, las estructuras de sentido necesarias e imprescindibles son aquellas que ayudan a enriquecer las relaciones sociales. Por sí solas, difícilmente podrán superar la asimetría social o mejorar la calidad de la existencia; pero sumadas a esfuerzos de otro tipo, pueden favorecer y hacer posible una transformación cualitativa de las condiciones históricas de la sociedad.

Por eso es tan importante, en mi opinión, adquirir conciencia sobre las adversas condiciones que las leyes del mercado hipercapitalista están imponiendo en el área de la industria editorial. Como afirma Pierre Lepape:

Algunos llegan a ver en la nueva economía del libro el modelo puro en que podría inspirarse un neocapitalismo globalizado: precariedad y desigualdad de estatuto de los 'trabajadores intelectuales' que son los autores, trabajo y remuneración intermitentes, premios a la creatividad y a la movilidad, criterios más duros de competencia y cooptación ${ }^{7}$.

La noción de World literature utilizada por Lepape apunta, justamente, a la pérdida de editoriales de avanzada, cuyos propósitos de originalidad y, sobre todo, de contestación son eliminados del mercado.

Atribuidos fundamentalmente a la producción editorial literaria, los criterios de la World literature suponen mecanismos mercantiles arbitrarios, basados de manera exclusiva en el afán de lucro: "En cuanto a la distribución, tres grandes cadenas (Bames \& Noble; Borders; y Book-A-Million) eliminaron poco a poco a la mayoría de

7. Pierre Lepape, "La dictadura de la World literature", Le Monde Diplomatique (edición chilena, traducción de Patricia Minarrieta), n. 39 (marzo 2004) 37. Lepape es autor, entre otros textos, de Le Pays de la Littérature (París: Seuil, 2003). 
los libreros independientes ya sea en provecho de sus megastores como de su circuito de ventas por internet". Lo que lleva a Lepape a opinar irónicamente: "Un escritor puede recibir el Premio Nobel de literatura y ser traducido a treinta lenguas, pero nunca pertenecerá a la World literature si no figura en pilas en las mesas de los megastores de Barnes \& Noble" ${ }^{\wedge}$. Por supuesto, lo dicho también es válido para la producción editorial no literaria.

Existen, asimismo, unos amenazantes criterios de censura que, de una u otra forma, se ponen de manifiesto en nuestro mundo cotidiano. En mi opinión, están vinculados con otras maneras de enfrentar las circunstancias históricas en que se desenvuelve nuestra existencia, de las que se desprenden procedimientos como las ilegales guerras preventivas, los asesinatos selectivos o la manipulación mediática. Este clima de pesimismo existencial del comienzo del siglo XXI — derivado de la perversión de la política internacional—influye en la producción y circulación de los libros. Por la naturaleza de las condiciones de producción editorial, los consumidores difícilmente pueden adquirir conciencia de los motivos que impiden que los libros que quieren leer estén en las librerías.

Un ejemplo de los mecanismos de censura en creciente desarrollo es el reciente invento en EE. UU. de un aparato que, instalado en el DVD, borra todas las imágenes consideradas no aptas para ser vistas por los niños. El criterio con que se establece la selección corresponde al puritanismo religioso al que se adscriben, entre otras importantes personalidades de ese país, los miembros de la actual administración. Realizadores de cine, como Spielberg y otros de su valía, han protestado por el cercenamiento de la libertad de expresión artística que tal invento produce. ¿No sería más efectivo que los propios niños aprendiesen qué programas o filmes son aptos para su desarrollo? ¿No correspondería a los padres y otros adultos de su círculo familiar educarlos y hacerles entender que determinados programas y

8. Ibíd, 36 . 
filmes no contribuyen al desarrollo de sus capacidades vitales? Traspasar tan importante proceso educativo a una máquina no parece ser el procedimiento más eficaz para lograr niños y futuros jóvenes intelectualmente sanos y equilibrados.

Dialécticamente, la falsa conciencia social que existe en ese país ha permitido la difusión e, incluso, la premiación de un documental de Michael Moore titulado "Bowling in Columbine", al que Luis Bocaz, en su reseña sobre Estúpidos hombres blancos, caracteriza como la "disección de la violencia latente en los Estados Unidos y de su permanente amenaza de desborde fuera de sus fronteras" ${ }^{\text {. En cuanto }}$ al libro de Moore reseñado, al que muchos consideran un panfleto, según Bocaz,

su historia es aleccionadora. La imprenta entregó, el 10 de septiembre de 2001, una partida de 50 mil ejemplares que quedó en bodega. Cuenta Moore que los editores le hicieron saber que, dado el cambio de clima político posterior a las Torres Gemelas, debería reescribirlo en un 50\% para su eventual aparición. Abreviemos. El libro salió sin modificaciones y logró un éxito arrollador. Best-seller en los Estados Unidos. Millones de ejemplares en más de 20 idiomas $^{10}$.

\section{La función sociocomunicativa de los textos}

Como dije al comienzo de esta reflexión, los libros son textos por cuyo intermedio fluyen las más diversas y disímiles formas de sentido en una semiosfera. Uno de los rasgos distintivos de ésta es su carácter restringido, manifiesto en la noción de frontera, cuya conceptualización supone la alternativa entre una mismidad y la otredad que la delimita:

9. Luis Bocaz, "Reseña de Estúpidos hombres blancos, de Michael Moore" (Barcelona: Ediciones B, 2003), en Le Monde Diplomatique (edición chilena), n. 38 (enero-febrero 2004) 38.

10. Ibídem. 
De lo dicho resulta evidente que el concepto de frontera es correlativo al de individualidad semiótica. En este sentido se puede decir que la semiosfera es una 'persona semiótica' y comparte una propiedad de la persona (...) Es sabido que la frontera de la persona como fenómeno de la semiótica históricocultural depende del modo de codificación ${ }^{11}$.

De acuerdo con esta aserción, todo texto es siempre otredad para quien lo reconoce.

La confrontación con la otredad del texto consiste en asignarle sentido desde la mismidad (también de sentido) que, hasta ese momento, ha constituido el soporte semiótico en que sustenta su identidad quien reconoce el texto: su lector, su destinatario. La lectura de un texto modifica inevitablemente la codificación de la frontera del lector; ya nunca más ese lector será la persona que era antes de leer (o reconocer) ese texto. Los libros son múltiples vías de transformación de la semiosfera de quienes los reconocen. Por esas vías o canales de modificación de fronteras culturales y semióticas, discurren las distintas y variadas estructuras de sentido capaces de transformar la calidad de la vida colectiva, perfeccionándola.

Cada texto moviliza sentido, flujo productor y reproductor de la semiosfera. El sentido es como la sangre: flujo vital del organismo ${ }^{12}$. Es significativa la observación de Lotman sobre la condición del texto en el plano de la semiótica de la cultura. En oposición a la idea de texto propuesta por la semiótica tradicional, en orden a considerarlo, por ejemplo, una señal de naturaleza unitaria, la semiótica de la cultura demuestra que no es un enunciado en un lenguaje cualquiera. Esto lleva a distinguir entre mensaje y texto: en el nivel del lenguaje natural, un enunciado puede funcionar como mensaje sin alcanzar la condición de texto. Así, antes del desarrollo de la dialectología, la

11. Lotman, La semiosfera, I, 24 y sgts.

12. Para Lotman, "todo el espacio semiótico puede ser considerado como un mecanismo único (si no como un organismo)", Lotman, La semiosfera, I, 24. Destacado por mí. 
lengua (o lenguaje verbal oral) era considerada una forma incompleta, si no incorrecta, de la escritura (lenguaje verbal escrito). En sentido contrario, un conjuro o una fórmula ritual codificados en una lengua olvidada (el celta antiguo, por ejemplo), son textos en los que se ha producido una reducción del lenguaje primario:

Para que un mensaje dado pueda ser definido como 'texto', debe estar codificado, como mínimo, dos veces. Así, por ejemplo, el mensaje definido como 'ley' se distingue de la descripción de cierto caso criminal por el hecho de que pertenece a la vez al lenguaje natural y al jurídico, constituyendo en el primer caso una cadena de signos con diversos significados, y en el segundo, cierto signo complejo con un único significado. Lo mismo se puede decir sobre los textos del tipo de la 'plegaria' y otros ${ }^{13}$.

En consecuencia, nuestro reconocimiento de un texto provoca un sentido.

La palabra 'provocar' es un derivado culto del verbo latino vocare 'llamar', a su vez derivado de vox, -cis 'voz'. El verbo latino provocare significaba 'llamar para que salga afuera; excitar, provocar' ${ }^{14}$. Los textos más provocativos, por consiguiente, son los que gritan y llaman a voces para que se reconozca el sentido. Los textos que, en nuestra semiosfera, satisfacen ese carácter son los que canalizan el sentido de resistencia a los mecanismos de sujeción que impiden el crecimiento de las personas, su acceso a la libertad.

La cultura del libro es mucho más que la organización empresarial de los trabajos editoriales. La cultura del libro es ajena a la tecnología de la edición de los textos y de su soporte material: el papel, el disco compacto o la red electrónica. La cultura del libro es el producto del 'trabajo' de los textos. Por otra parte, y volviendo a las

13. Lotman, La semiosfera, $I, 78$.

14. Joan Corominas, Diccionario crítico etimológico del a lengua castellana, IV vols. (Madrid: Gredos, 1974) s. v. voz, 764 y sgts. 
lúcidas observaciones de Lotman, "la cultura en su totalidad puede ser considerada como un texto. Pero es extraordinariamente importante subrayar que es un texto complejamente organizado que se descompone en una jerarquía de 'textos en los textos' y que forma complejas entretejeduras de textos" 15 . El trabajo de los textos, para la semiótica de la cultura, consiste en su función sociocomunicativa, que puede reducirse a los siguientes procesos: a) el trato entre el destinador y el destinatario, b) el trato entre el auditorio y la tradición cultural, c) el trato del lector consigo mismo, d) el trato del lector con el texto y e) el trato entre el texto y el contexto cultural ${ }^{16}$.

En esta red de relaciones se forja la valía de los libros y de su productividad en la semiosis. El trabajo que desempeñan ha de redundar en un beneficio social en la medida en que contribuyan a que, desde su condición de frontera y otredad, permitan que los lectores adquieran conciencia de su mismidad en condiciones de sometimiento. Por lo mismo, en ese proceso liberador han de hacer posible el desarrollo de una conciencia crítica capaz de evaluar los mecanismos de sometimiento y, a la vez, valorar la necesidad permanente de que las relaciones sociales sean regidas por la solidaridad y el respeto a la vida.

Un caso ejemplar del trabajo semiótico de los textos es el libro que Mijaíl Bajtín dedica al rescate de los valores culturales de la risa popular en la Edad Media y el Renacimiento ${ }^{17}$. La rigurosa y prof unda investigación del sabio ruso hace posible comprender que los textos de Rabelais son, en su época, profundamente transgresores. La cultura cómica popular y, en especial, la cultura carnavalesca se oponían a la cultura oficial, "al tono serio, religioso y feudal" de los agentes sociales del sometimiento. También en la obra de Shakespeare y en la de Cervantes subsisten los ecos de ese texto colectivo no verbal que es la risa popular, la única válvula de escape de los oprimidos frente

15. Lotman, La semiosfera, $I, 109$.

16. Lotman, La semiosfera, I, 77-82 (V. nota 4).

17. Mijaíl Bajtín, La cultura popular en la Edad Media y el Renacimiento. El contexto de François Rabelais (traducción de Julio Forcat y César Conroy, Madrid: Alianza Editorial, 1987). La edición original, en ruso, es de 1940. 
a quienes los dominan. Pero es, sobre todo, en los textos de Rabelais donde queda en evidencia la tarea de

destruir el cuadro oficial de la época y de sus acontecimientos, en lanzar una mirada nueva sobre ellos, en aclarar la tragedia o la comedia de la época desde el punto de vista del coro popular que se ríe en la plaza pública. Rabelais moviliza todos los medios de la imaginería popular lúcida para extirpar de las ideas relativas a su época y a sus acontecimientos, todo mensaje oficial, toda seriedad limitada, dictada por los intereses de las clases dominantes ${ }^{18}$.

Los artículos de opinión de Álvaro Quesada Soto constituyen, en nuestro medio y en nuestra época, un texto igualmente transgresor $^{19}$. Como homenaje a la memoria de un amigo tan querido $y$ recordado, comentaré muy brevemente el trabajo semiótico de su texto "Mathelmáticas", publicado en el Semanario Universidad $(1991)^{20}$, en el que critica la falacia de los argumentos del entonces ministro Thelmo Vargas, expuestos en un artículo titulado "Dos más dos son cuatro", para justificar la política de ajustes estructurales o privatización que el Gobierno de ese momento pretendía llevar adelante.

Desde el título, el escalpelo irónico de la escritura de Álvaro Quesada pone en entredicho la aparente solvencia economicista del Ministro a quien, por su condición profesional, se le considera experto en matemática. Es verdad que la intención del artículo está lejos de cuestionar los conocimientos de matemática del Ministro. Por el contrario, la ironía en el tratamiento del asunto pone en evidencia que, con argumentos matemáticos, el señor Vargas quiere persuadir a la ciudadanía de que las privatizaciones previstas por el Gobierno constituyen un bien social:

18. Ibíd., 395 y sgts.

19. Álvaro Quesada Soto, “Artículos de opinión”, Herencia, 13, 2 y 14, 1 (2003) 48-108.

20. Loc. cit., 91 y sgts. Las citas corresponden a esta versión. 
El problema del país, según el Gran Dictador de este gobierno chaplinesco, consiste en que mucha gente exige al Gobierno gastar más de lo que está dispuesta a darle en impuestos o, expresado en una originalísima metáfora, exigen 'hacer chocolate sin cacao'. ¿Quiénes son ésos que piden más de lo que dan en impuestos, que pretenden tomar chocolate sin producir cacao? Las matemáticas de Thelmo cuidadosamente lo ocultan pero exhiben como conclusión lógica —que todos debemos respetar aunque no lo queramos - la única idea que parece haber alumbrado este oscuro gobierno: 'hay que reducir el gasto público', lo cual equivale según la lógica de las matemáticas thelmoeuclidianas a 'privatizar'. No hay duda: dos más dos son cuatro. Pero, ¿quién va a trabajar para producir el cacao y quién se va a beber el chocolate?

Si se repara en los términos que destaqué, la ironía se hace evidente: la metáfora "originalísima" es una expresión coloquial común en el castellano costarricense. El Gobierno es “oscuro" como, a veces, las explicaciones matemáticas, sobre todo cuando con ellas se quiere ocultar el verdadero propósito del asunto. "Alumbrar" juega con sus dos significados comunes: 'iluminar' y 'parir': por un lado, la privatización es la única luz en medio de la oscuridad del Gobierno, $\mathrm{y}$, por otro, es la única idea que el Gobierno ha parido.

Los ejemplos vistos son apenas la punta del iceberg: el artículo está lleno de procedimientos similares que, de acuerdo con el estilo de Álvaro Quesada, mueven a la risa aunque, a la vez, ponen en evidencia los abusos del poder que nos convierten en víctimas. El recurso paródico es característico en sus artículos de opinión, porque la parodia exige reconocer y comprender el sentido de un texto mediante un proceso de inversión de los significados; en eso consiste su carácter lúdico, portador del dispositivo de la risa.

En la conclusión del párrafo citado, el autor menciona el título del artículo del Ministro para someterlo a la transformación paródica 
con la que jugará a lo largo del texto: saber sumar equivale a someterse a las políticas neoliberales de privatización. Con este juego, cierra así su artículo:

La Biblioteca Nacional, que sabe sumar muy bien, of reció recientemente en su afanosa búsqueda de cacao, la mejor demostración de lógica thelmoencefálica, y nos ayudó a vislumbrar lo que será el paraíso al que aspira el gobierno: un país donde el único papel que circule sea el papel moneda y los libros de historia sólo sirvan para limpiarse el culo ${ }^{21}$.

\section{Las andaduras del sentido}

Como puede apreciarse en el recurso de la inserción del libro en el libro, con el que inicié estas reflexiones, una de las funciones básicas de los textos es la generación de nuevos sentidos. El hecho de que Don Quijote se entere de que sus aventuras andan en libros sucede en un acontecimiento narrado en un texto de ficción. Don Quijote es un ser ficticio, un personaje de este texto de ficción. Sin embargo, los libros a que se alude en el acontecimiento en cuestión son reales; pertenecen a la edición de la primera parte de la novela de Cervantes. ¿Cuál es la realidad o cuál es la ficción? Este no es el problema, es sólo un juego propuesto en la producción de sentido a través del texto: relación entre el destinador y el destinatario, mediada, a su vez, por la relación con la tradición cultural que supone la confrontación con la otredad que el texto representa en su semiosfera.

La legitimación del relato ficticio como historia de sucesos reales, que permite convertir en seres históricos a los personajes de la ficción, es uno de los propósitos del recurso. El texto ha generado un sentido superpuesto al del acontecimiento narrado. Pero no es el único: en su contexto punza la aparición del Quijote de Avellaneda. El

21. Alude a un hecho histórico ocurrido entonces: funcionarios de la Biblioteca Nacional "reciclaron" libros que estaban en bodegas por falta de espacio en las estanterías. 
reflejo del texto en el texto deslegitima ese libro apócrifo: otra veta de sentido producida en el soporte textual.

La risa popular de la plaza pública es un texto; examinada en el contexto medieval produce un sentido muy diferente del que suele asignársele cuando se manifiesta como texto en espectáculos públicos de nuestro tiempo. Bajtín ha recuperado ese sentido pretérito en el libro antes aludido. Un texto del refranero popular costarricense: "no puede hacerse chocolate sin cacao", sirve como pretexto en el artículo de opinión de Álvaro Quesada para criticar las políticas neoliberales de un gobierno de la pasada década, aunque el texto genera sentido también en la actualidad.

En fin, la reflexión hace evidente la importancia que tiene el objeto semiótico llamado libro en la construcción de un sentido crítico, cuyo trabajo semiótico procura liberar a sus lectores de las ataduras provocadas por estereotipos y prejuicios, para permitirles el tránsito hacia la libertad. En el día consagrado a reconocer su valor social, deseémosle larga y fecunda existencia. 